\title{
Computational simulation of heat conduction on different surfaces
}

\author{
Gheorghe Daniel Florea ${ }^{1 *}$, Nicolae Ioan Vlasin ${ }^{1}$, Adrian Bogdan Șimon-Marinică ${ }^{1}$, \\ Florin Manea ${ }^{1}$ and Zoltan Vass ${ }^{1}$ \\ ${ }^{1}$ National Institute for Research and Development in Mine Safety and Protection to Explosion - \\ INCD INSEMEX Petroşani, Romania
}

\begin{abstract}
The heat conduction from the initiation source to the adjacent surfaces, is a physical phenomenon worth considering in the process of analysing the fire. This complex phenomenon describes how the transport, the exchange, and the redistribution of the thermal energy are carried out. It is based on the theoretical knowledge that describes the initiation and fire evolution in time. The flames transfer heat from nearby surfaces through two distinct physical processes, namely convection and radiation. Another way of heat transfer is conduction, in which case the transfer of heat implies the existence of an environment that can be of a gaseous, liquid or solid nature. This paper illustrates a brief presentation of how the heat transfer is carried out, the influence of the three phenomena on the mechanism of initiation and development of the fire, and can be seen as well as a case study aimed at the computerized simulation of a fire, having as a source of initiation the radiative transfer of heat to the surrounding combustible surfaces. The ignition of the different materials in a room, due to radiation exposure emitted by an incandescent source at a certain distance from them, even without having a direct contact to the flames, is a common reality in the case of fires that occur in both residential and industrial environments. This fact justifies the importance of thermal radiation study.
\end{abstract}

\section{Introduction}

Heat transfer represents a distinct area of thermodynamics that characterizes the exchange of heat between two bodies, two regions of the same body, or two fluids, a process determined by the difference in temperature between them. This complex phenomenon describes the ways in which the transport, exchange, and redistribution of thermal energy are carried out and plays an important role in the study of the fire mechanism.

Respecting the two principles of thermodynamics, heat transfer is achieved in three ways: by conduction, convection, and radiation. These modes can exist separately or, in most cases, combined, in complex heat exchange processes [1].

\footnotetext{
* Corresponding author: daniel.florea@insemex.ro
} 
In the case of thermal conduction, energy is progressively transferred, from a region with a higher temperature to a region with a lower temperature, inside the environment (solid, liquid, or gaseous), or between different surfaces placed in direct physical contact, under the influence of a temperature difference, without the existence of an apparent movement of the particles that make up those environments [2].

Thermal convection is a process of heat transfer through the combined action of thermal conduction, internal energy accumulation and mixing motion. When a direct contact and a relative movement between a solid surface and a fluid (either liquid or gas) exist, convection is the most important mechanism of heat exchange. The phenomenon of thermal convection is always accompanied by conduction and radiation.

Thermal radiation is the process by which heat is transferred from a body with a higher temperature to a body with a lower temperature, the bodies being separated in space. In this case, the transport of energy is not done through a material, as in the case of conduction, nor in the form of a flow through a liquid form or through air, as in the case of convection. Energy is transmitted through electromagnetic waves, as energy quanta, similar to the sun's rays. It travels in straight lines at the speed of light. The heat from the rays can be absorbed by combustible materials which causes them to heat up and possibly ignite [3].

In practical fire modelling scenarios, radiation is the dominant mode of heat transfer [4]. When analysing the mechanism of initiation and development of a fire, the theoretical notions that describe heat transfer play an important role $[5,6]$. In the initial stages of the fire, in which there is still a clear distinction between the upper and lower layers and a clear delimitation of the initial fire plume, the rate of fire growth is usually unaffected by the existence of oxygen. At this stage, the fire is fuel-controlled, the growing rate of the fire being proportional and limited by the availability of combustible material. The fire develops as long as the fuel can be vaporized in sufficient quantity and mixed locally with air at a temperature high enough to support the combustion in the fire outbreak. The HRR of the fire at any given time depends on the mass-burning rates and flaming areas of the different fuels that are involved in the fire. These then dictate the amount of heat energy generated by the fire as well as the temperature distribution in the enclosure.

Convection is the main mode of heat transfer during the primary stages of fire development when the fire plume is small and radiation heat transfer is limited. The hot gases produced by the fire exchange heat with the environment by convection, as they follow their upward flow to and across the ceiling of the room, heating both the ceiling and any other surface with which it comes into contact. Moreover, the hot smoke that accumulates near the ceiling is also emitting thermal radiation on the environment, throughout the life of the fire.

As the surfaces in the vicinity of the fire heat up, the thermal radiation emitted by the ceiling and walls increases in intensity, combining with the thermal radiation in the upper layer, leading to its preheating and then to the initiation of pyrolysis. Therefore, heat transfer through radiation plays a major impact on the fire environment as the fire continues to increase. The spread of the fire will be carried out later by igniting objects and combustible materials under the influence of any form of heat transfer (radiation, conduction, and convection). Very often, however, the ignition of nearby objects occurs due to high thermal radiation, both from flames and from the high temperature of gases and smoke resulting from combustion, located in the upper layer.

Figure 1 shows the three forms of heat transfer, to facilitate the understanding of these thermodynamic processes. 


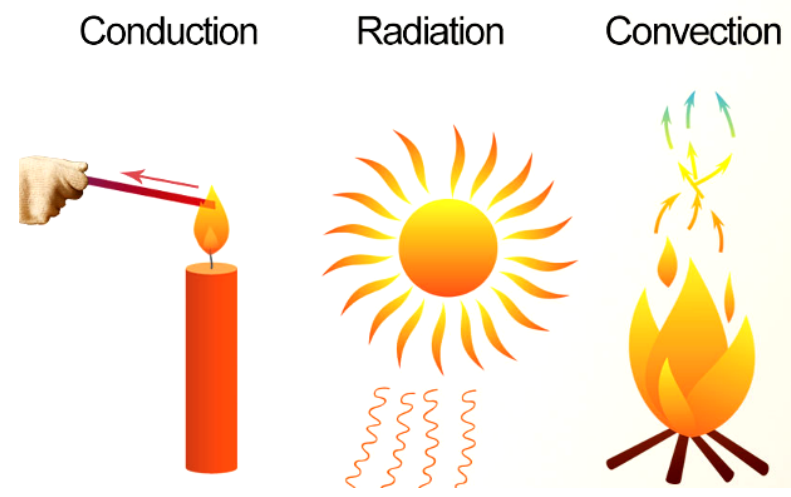

Fig. 1. Forms of heat transfer

In this paper, the authors aim to present the important role that radiative heat transfer plays in the case of fires in residential and industrial environments if the ignition source is not in direct contact with nearby combustible materials. By computational simulation of a fire scenario, using FDS techniques and the Pyrosim user interface, the paper numerically validates the basic principle of thermal radiation, namely that the closer the material is to the fire the more radiated heat it will receive, leading to the development and spread of fire in the studied space.

\section{Materials and methods}

The article presents some results obtained in a study conducted following a fire occurred in a residential house, in order to determine the causes and circumstances that led to the occurrence of the event. One of the main objectives of a post-event technical expertise is precisely to determine the probable source of initiation of the event, as well as the place of initiation [7].

In order to run the computational simulation of the fire scenario, the virtual geometry of the whole room was developed, on a real scale, the dimensions of the computational domain being (L x W x H): $4.2 \mathrm{~m} \times 4.4 \mathrm{~m} \mathrm{x} 3.0 \mathrm{~m}$. For the FDS analysis of the fire, the geometry obtained was discretized in a number of 465,120 rectangular cells (mesh cells), by $0.05 \mathrm{~m} \mathrm{x}$ $0.05 \mathrm{~m} \times 0.05 \mathrm{~m}$, distributed in a number of 34 mesh subdivisions, in order benefit of the parallel processing facility.

For a better view, the room ceiling has complete transparency, but its features have been fully taken into account.

The virtual geometry for the simulated scenario respected the elevation of the site affected by the fire, and the objects involved in the simulation respected the physico-chemical characteristics of the real homologous objects (walls, wood, plastic, textile, etc.). The following were used as combustible materials: textile materials (clothes, placed to dry near the stove), wood material (wood panelling, furniture, carpentry, etc.), plastic material (PVC - electrical and electronic equipment), polyurethane foam (sofa, mattresses, etc.).

The complete geometry of the analysed room is presented in figure 2 . 


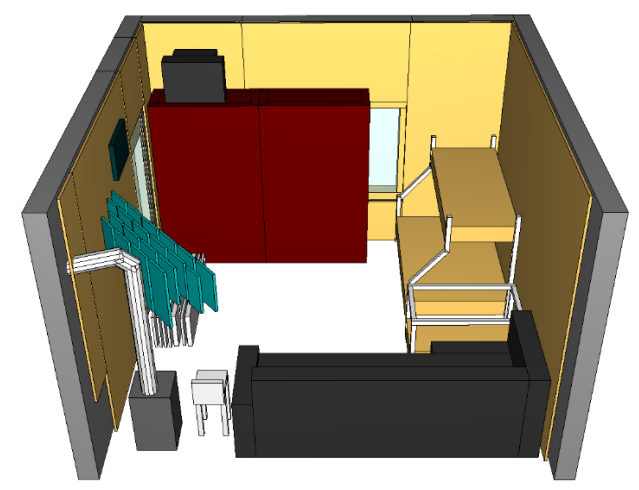

Fig. 2. Room geometry used for FDS simulation

The physical and thermal characteristics of some materials presumed to be involved in the fire are included in table 1.

Table 1. Physical and thermal characteristics materials

\begin{tabular}{|c|c|c|c|c|c|c|}
\hline Material & $\begin{array}{c}\text { Density } \\
{\left[\mathbf{k g} / \mathbf{m}^{3}\right]}\end{array}$ & $\begin{array}{c}\text { Specific Heat } \\
{[\mathbf{k J} / \mathbf{( k g} \cdot \mathbf{K}]}\end{array}$ & $\begin{array}{c}\text { Thermal } \\
\mathbf{C o n d u c t i v i t y} \\
{[\mathbf{W} /(\mathbf{m} \cdot \mathbf{K})]}\end{array}$ & $\begin{array}{c}\text { Heat of } \\
\mathbf{C o m b u s t i o n} \\
{[\mathbf{k J} / \mathbf{k g}]}\end{array}$ & $\begin{array}{c}\text { Heat } \\
\text { Release } \\
\text { Rate per } \\
\text { Area } \\
{\left[\mathbf{k W} / \mathbf{m}^{2}\right]}\end{array}$ & $\begin{array}{c}\text { Ignition } \\
\text { Temperature } \\
{\left[{ }^{\circ} \mathbf{C}\right]}\end{array}$ \\
\hline Wood & 640 & 2,85 & 0,14 & 17000 & 200 & 240 \\
\hline PVC & 1380 & $\begin{array}{c}1,29\left(23^{\circ} \mathrm{C}\right) \\
1,35\left(50^{\circ} \mathrm{C}\right) \\
1,47\left(100^{\circ} \mathrm{C}\right) \\
1,59\left(150^{\circ} \mathrm{C}\right)\end{array}$ & $\begin{array}{c}0,192\left(23^{\circ} \mathrm{C}\right) \\
0,175\left(50^{\circ} \mathrm{C}\right) \\
0,147\left(100^{\circ} \mathrm{C}\right) \\
0,134\left(150^{\circ} \mathrm{C}\right)\end{array}$ & 20000 & 312 & 390 \\
\hline Plastic & 950 & 1,67 & 0,18 & 31000 & 400 & 349 \\
\hline Textile & 240 & 1,357 & 0,1 & 17000 & 250 & 220 \\
\hline $\begin{array}{c}\text { Polyureth } \\
\text { ane foam }\end{array}$ & 40 & 1,00 & 0,05 & 30000 & 250 & 310 \\
\hline
\end{tabular}

The study aimed to determine the possibility of fire initiation by indirect contact, between the stove pipe and clothing placed in its vicinity, at a sufficiently small distance (minimum $20 \mathrm{~cm}$ ), through the radiative thermal field. Figure 3 shows the virtual geometry of the area in the vicinity of the initiation source (solid fuel stove - wood).

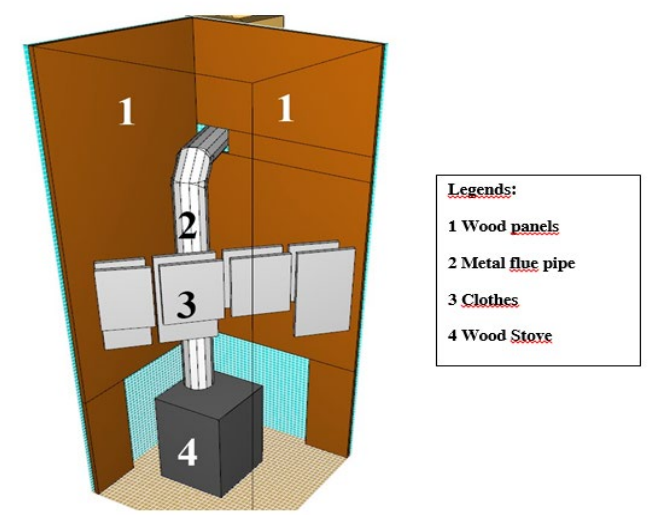

Fig. 3. Virtual geometry of the area in the vicinity of the ignition source 
In this sense, the geometry of the analysed area was made, with the following dimensions ( $\mathrm{L}$ x W x H): 1m x 1m x 3m, subsequently discretized in a number of 201,720 rectangular cells (mesh), with the resolution of $1 \mathrm{~cm} \times 1 \mathrm{~cm} \times 1 \mathrm{~cm}$. The results obtained after solving the analysed scenario demonstrate the possibility of fire ignition in the vicinity of the stove, due to the exposure of dry clothes at a short distance from the hot metal flue pipe at a temperature greater than $300{ }^{\circ} \mathrm{C}$, by radiative heat transfer phenomenon.

\section{Results and discussions}

The decomposition of materials due to fire is called Pyrolysis. Although textile fibres in their natural form are inherently fire retardants, however, when the surrounding temperature reaches above the flash point temperature of fibres, they catch fire. They decompose into flammable fragments, which generate heat. This heat further decomposes the cellulose to carry on the decomposition process. Thermal decomposition of cellulose leads to the formation of products like liquids, tar and solid materials. Bond rupture, bond reformation, volatilization and many exothermic reactions occur simultaneously. Catching of fire and its progress in textiles is mainly due to the formation of various gases and liquids during burning of fibre.

Along with the intensification of the combustion process - the fire in the stove also takes place the heating of the metallic elements of the stove (hob, pipe, side walls), which generates a significant thermal radiative field, capable of heating the air in the bedroom and the exposed drying clothes.

As a result of the thermal radiative field, manifested intensely in the vicinity of the metallic elements of the stove (hob and pipe), the ignition of clothes/materials with combustion properties has occurred.

Cotton, from which most current textiles are made, needs a lower heat absorption capacity (170 times lower than that of wood). Therefore, ignition can be achieved from sources of low thermic level. The ignition duration and the flame propagation rate for textiles depend on the weight of the material per unit area and the structure of the fabric [8]. The ignition of the textile material, following the exposure to a temperature higher than its ignition temperature, in a point located at the lower edge determines the initial propagation of the flame both laterally and upwards, the lateral propagation reducing the propagation in the longitudinal direction.

After igniting the clothes / combustible materials in the vicinity of the stove/pipe, due to the impossibility/inability to intervene to extinguish the incipient fire, the fire develops inside the bedroom vertically and horizontally. A major role in the rapid-fire evolution is played by the ignition source location [8], in a room corner, together with the dry wood panels covering the walls. Corner fires are currently known for their fire growth potential of a combustible lining material $[9,10]$.

In the next sequence of images (Fig. 4 to Fig. 7), this phenomenon is represented, starting from the presumed source of initiation, to the ignition of combustible materials (clothes put to dry at a short distance from the stove), then the propagation of the flame front to the wood panelling on the walls of the room. 


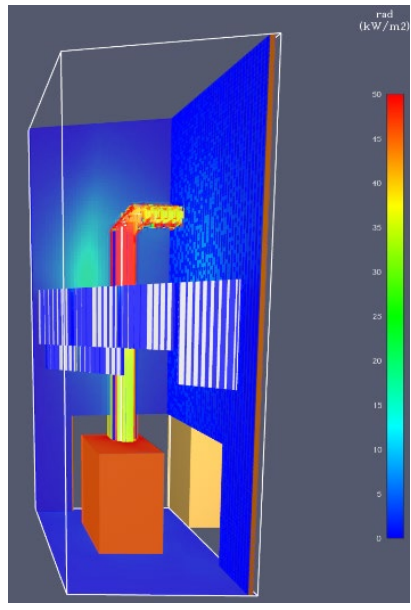

a)

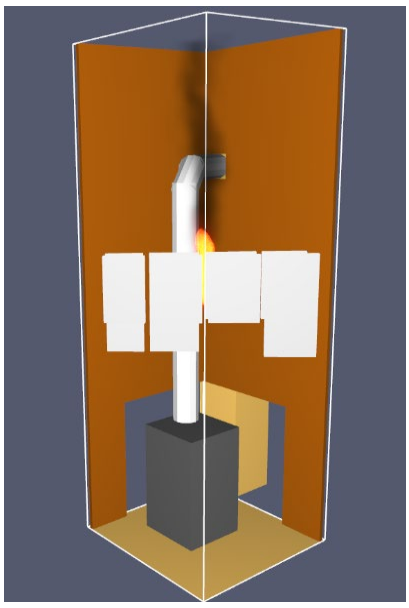

b)

Fig. 4. Ignition of textile materials (clothes), by thermal radiative field a) Radiative heat flux at the textile material level; b) Initial ignition of textile materials, exposed to thermal radiation
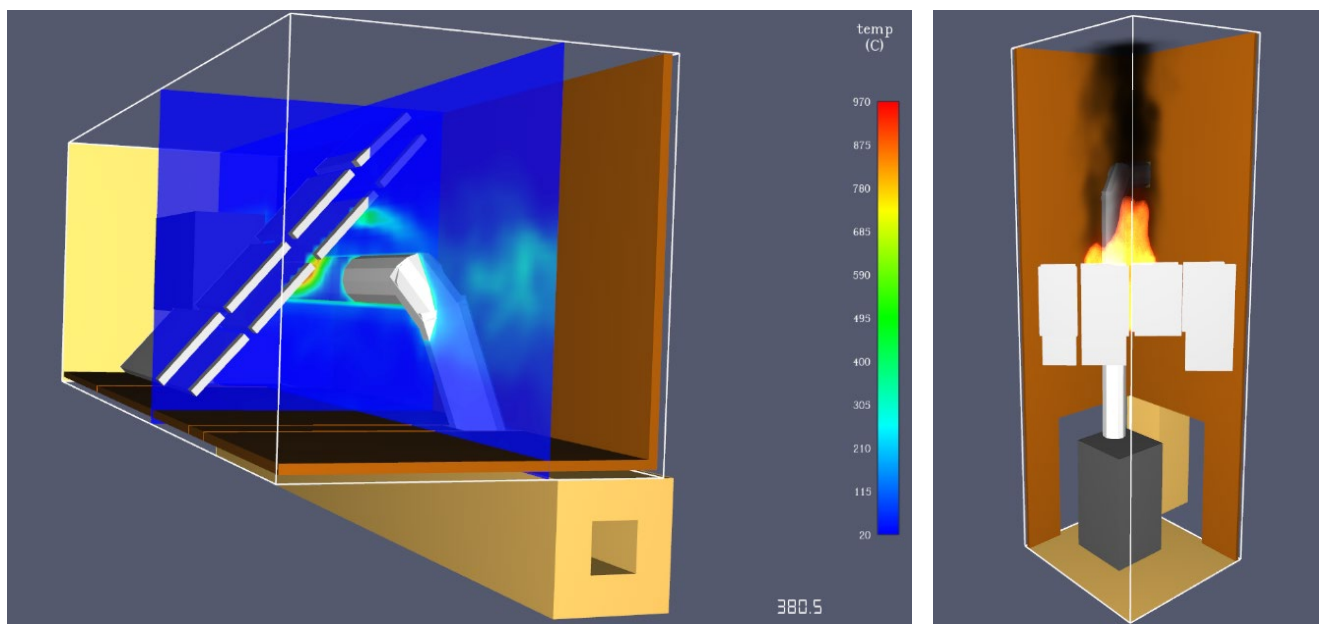

Fig. 5. Ignition of textile materials, fire development 

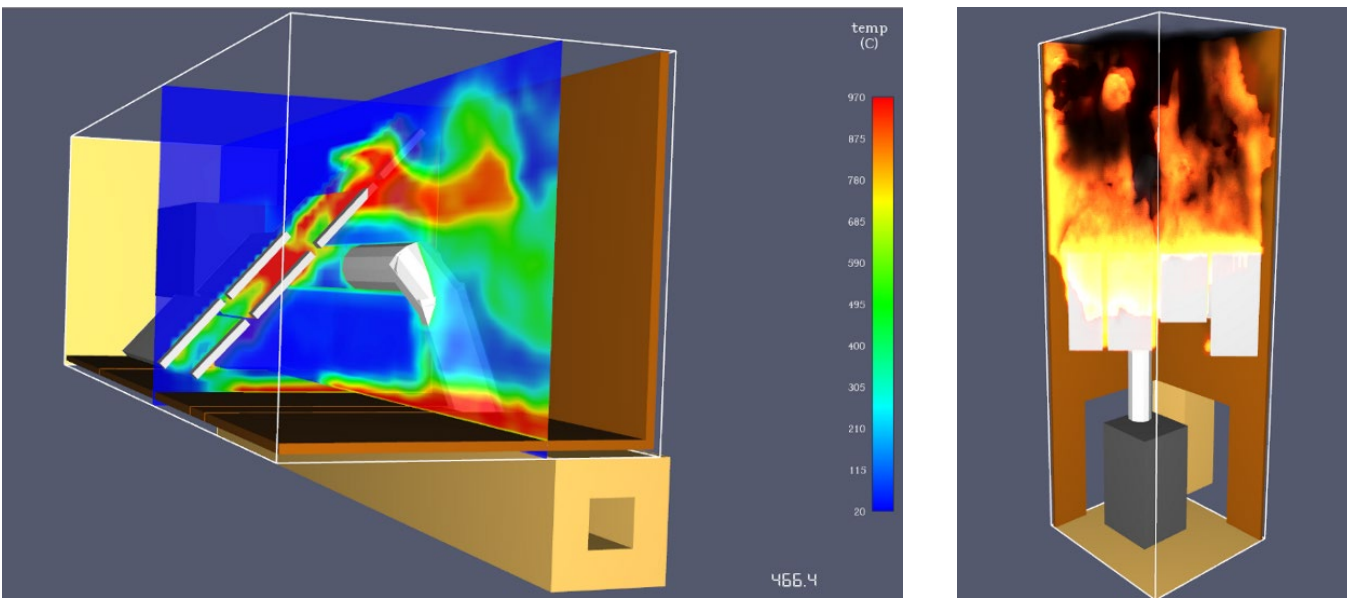

Fig. 6. Fire front propagation to wall wood panelling
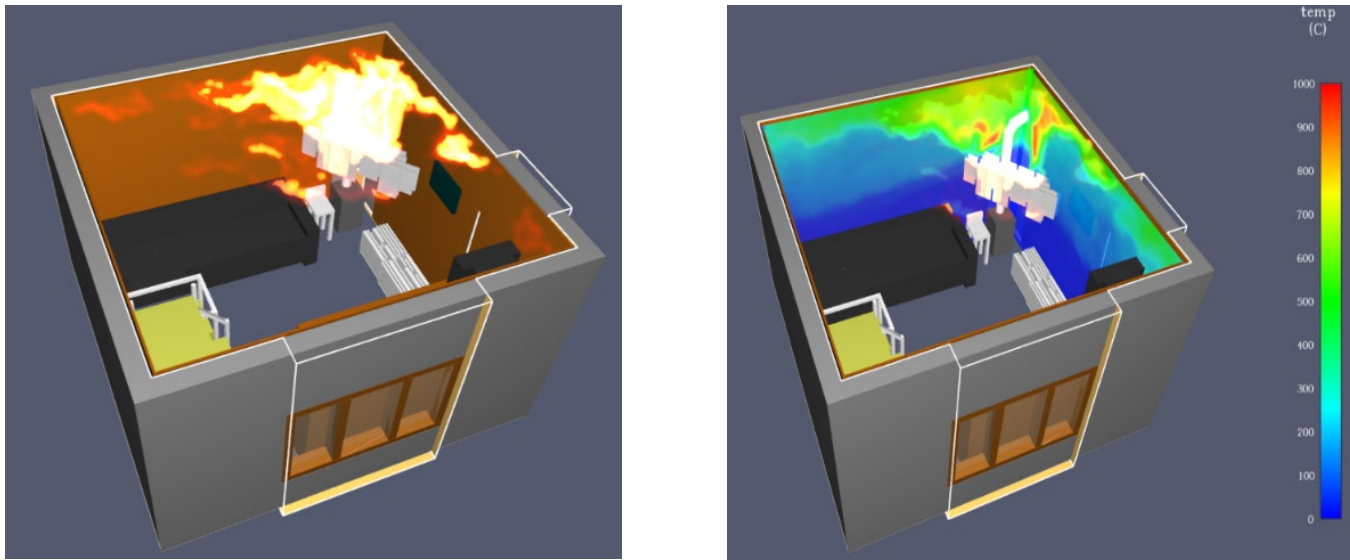

Fig. 7. Development of the flame front and migration at the ceiling, to the opposite side of the room, by convective transfer

\section{Conclusions}

The aim of the paper was to present the main physico-chemical mechanisms through which the heat transfer is performed, in case of fires. This energy transfer is of major importance both in fire safety engineering and in the analysis of the combustion phenomenon, as a stage of investigation.

The computer simulation of the proposed fire scenario demonstrated the ability of the FDS technique to model the heat exchange between the ignition source and the surrounding solid surfaces, especially the radiative transfer component, whose contribution was followed by the authors.

The results showed that, although convection is the primary mode of heat transfer during the early stages of fire growth, the radiative heat fluxes from a hot surface, placed in the immediate proximity of some flammable materials or objects, can lead to the initiation of fire, in this case we can speak of the existence of an ignition source without direct contact. 
The room environment effects due to the initial fire plume location in the room corner, together with the dry wood panels covering the walls, are favourable factors that explain the rapid development of the fire and its further generalization in the entire room, under the combined contribution of radiation, convection and conduction (e.g., from the fire plume, hot objects or hot ceiling gases).

\section{Acknowledgements}

This paper was developed within the Nucleu-Programme, carried out with the support of Romanian Ministry of Research and Innovation, project no. PN-19-21-01-05, project title: Fundamental research and computer simulations on the initiation of explosive gas mixtures by potential sources of ignition of a different nature (in Romanian: Cercetari fundamentale si simulari computerizate privind initierea amestecurilor gazoase explozive prin surse potentiale de aprindere de natura diferita).

\section{References}

1. M. C. Suvar, N. I. Vlasin, V. M. Pasculescu, E. Ghicioi; -Proceedings of 16th International Multidisciplinary Scientific Geo Conference SGEM 2016, Informatics, Geoinformatics and Remote Sensing- 1, 25-32 (2016)

2. D. Pasculescu, L. Lupu, V. M. Pasculescu, I. Inisconi, M. C. Suvar, Environmental Engineering and Management Journal, 11, 1267-1271, (2012)

3. M. Prodan, E. Ghicioi, I. Nălboc, A. Szollosi-Moța, 7-th International Multidisciplinary Symposium "Universitaria Simpro 2016" - 199-244, (2016)

4. A. B. Șimon-Marinică, E. Ghicioi, N. I. Vlasin, M. C. Șuvar, G. D. Florea, 19-th International Multidisciplinary Scientific Geo Conference - SGEM 2019 Conference Proceedings, 1165- 1171 (2019)

5. D. Pasculescu, L. Pana, V. M. Pasculescu, F. Deliu, Mining of Mineral Deposits, 13 (2), 1-16, (2019)

6. V. M. Pasculescu, N. I. Vlasin, E. Ghicioi, G. D. Florea, M.C. Suvar, Environmental Engineering and Management Journal, 18 (4), 889-900, (2019)

7. M. C. Suvar, D. Cioclea, V. Arad, C. Lupu, N. I. Vlasin, Environmental Engineering and Management Journal, 16, 1373-1381, (2017)

8. V. M. Pasculescu, M. C. Suvar, N. I. Vlasin, G. A. Gaman, D. Florea, Proceedings of 15 th SGEM Geo Conference on Informatics, Geoinformatics and Remote Sensing, 1, 77-84. (2015)

9. N. I. Vlasin, C. Lupu, E. Ghicioi, E. Ghicioi, C. Tomescu, Environmental Engineering and Management Journal, 13, 1439-1444. (2014)

10. Pyrosim User Manual, 2014, Available on http://www.thunderheadeng.com/pyrosim/resources/ 